\title{
Analisis Determinan Berat Badan Lahir Rendah (BBLR) Di Provinsi Nusa Tenggara Timur Tahun 2017
}

\author{
Elina Mayasari', Geraldi Putra Prasetya Balebu ${ }^{2}$, \\ Latifah Hasanah $^{3}$, Rizka Wulandari ${ }^{4}$, Rani Nooraeni ${ }^{5}$ \\ 1,2,3,4,5 Program Studi Diploma IV, Jurusan Statistika Sosial dan Kependudukan, \\ Politeknik Statistika STIS, \\ Jakarta 11480, Indonesia \\ 211709655@stis.ac.id;211709713@stis.ac.id; \\ 211709782@stis.ac.id;211709982@stis.ac.id; raninoor@stis.ac.id
}

\begin{abstract}
Health is one of the essential needs for human beings, and even became a major issue that indicates achievement of a country or a region. Health can also be viewed from the condition of the infants, which can be measure from Infant Mortality Rate (IMR). This indicator shows a high rate especially because of low birthweight. The cases of low birthweight is one of the highest case that occurred in developing countries, including Indonesia. Nusa Tenggara Timur (NTT) province in Indonesia, is one of the most common places where this case is most likely to happened. The percentage of the low birthweight case is higher than the average case in Indonesia. Therefore, this research paper aim to investigate variables which are responsible for causing low birthweight case in such a high number in NTT on 2017. The method used for analysis is logistic regression. The result indicate that mother's education level is significantly affecting low birthweight cases in NTT.
\end{abstract}

Keyword - Low Birthweight; logistic regression; education level.

\begin{abstract}
ABSTRAK
Kesehatan merupakan hal yang primer bagi setiap manusia, bahkan menjadi salah satu tolak ukur keberhasilan suatu negara, terutama kesehatan pada bayi yang ditunjukkan dengan angka kematian bayi. Angka Kematian Bayi (AKB) yang tinggi salah satunya disebabkan oleh kondisi berat badan lahir rendah (BBLR). Kasus Berat Badan Lahir Rendah (BBLR) masih menjadi permasalahan sebagian besar negara berkembang yang persentase $B B L R$ nya lebih tinggi dibandingkan rata - rata nasional. NTT merupakan salah satu provinsi di Indonesia yang masih menghadapi masalah kualitas kesehatan, salah satunya ditunjukkan dengan kasus BBLR tertinggi. Untuk itu, penelitian ini bertujuan untuk mengkaji mengenai variabel - variabel yang memengaruhi BBLR di Provinsi Nusa Tenggara Timur tahun 2017. Metode analisis yang digunakan adalah regresi logistik. Berdasarkan hasil penelitan, didapatkan bahwa tingkat Pendidikan ibu berpengaruh signifikan terhadap kasus BBLR di NTT.
\end{abstract}

Kata Kunci - BBLR; Logistik; Tingkat Pendidikan .

\section{PENDAHULUAN}

Kesehatan merupakan suatu bentuk dari kebutuhan dasar manusia. Dari sekian banyak indikator kesehatan, salahsatunya adalah Angka Kematian Bayi (AKB). Angka kematian bayi (AKB) adalah banyaknya bayi yang meninggal sebelum mencapai usia 1 tahun yang dinyatakan dalam 1.000 kelahiran hidup pada tahun yang sama.

Salah satu penyebab tingginya angka kematian bayi (AKB) adalah berat badan lahir rendah (BBLR) (Depkes, 2015). Berat badan lahir merupakan salah satu indikator dalam tumbuh kembang anak hingga masa 
dewasanya dan menggambarkan status gizi yang diperoleh janin selama dalam kandungan. Pada negara berkembang, berat badan lahir rendah (BBLR) masih menjadi salah satu permasalahan defisiensi zat gizi. BBLR ialah bayi yang dilahirkan dengan berat badan kurang dari 2.500 gram, tanpa memandang masa gestasi (Kosim, 2012).

Kejadian berat badan lahir rendah (BBLR) dianggap sebagai indikator kesehatan masyarakat karena erat hubungannya dengan angka kematian, kesakitan, dan kejadian kurang gizi dikemudian hari. Menurut WHO, pada tahun 2015, di dunia terdapat kejadian BBLR sebesar 15,5\%, yang berarti sekitar 20,6 juta bayi tersebut lahir setiap tahunnya yang mengalami kejadian BBLR. Kejadian BBLR 96,5\% di antaranya di negara-negara berkembang. Indonesia sebagai salah satu negara berkembang masih berada pada posisi yang cukup tinggi untuk kasus BBLR.

Berdasarkan data SDKI, angka kejadian BBLR di Indonesia pada tahun 2017 masih relatif tinggi yaitu sebesar 7,1\%. BBLR akan membawa risiko kematian, gangguan pertumbuhan dan perkembangan anak jika tidak tertangani dengan baik.salah satu wilayah di Indonesia yang masih menghadapi berbagai tantangan sumber daya untuk meningkatkan kualitas kesehatan dan pendidikan anak ialah Provinsi Nusa Tenggara Timur. Hal tersebut salah satunya dapat terlihat dari persentase BBLR yang ada di Provinsi Nusa Tenggara Timur yang merupakan provinsi yang mempunyai persentase BBLR tertinggi di Indonesia tahun 2017 yaitu sebesar 13,43\%. Hal ini menunjukkan bahwa Provinsi Nusa Tenggara Timur mengalami BBLR hampir dua kali lipat dari rata-rata nasional.

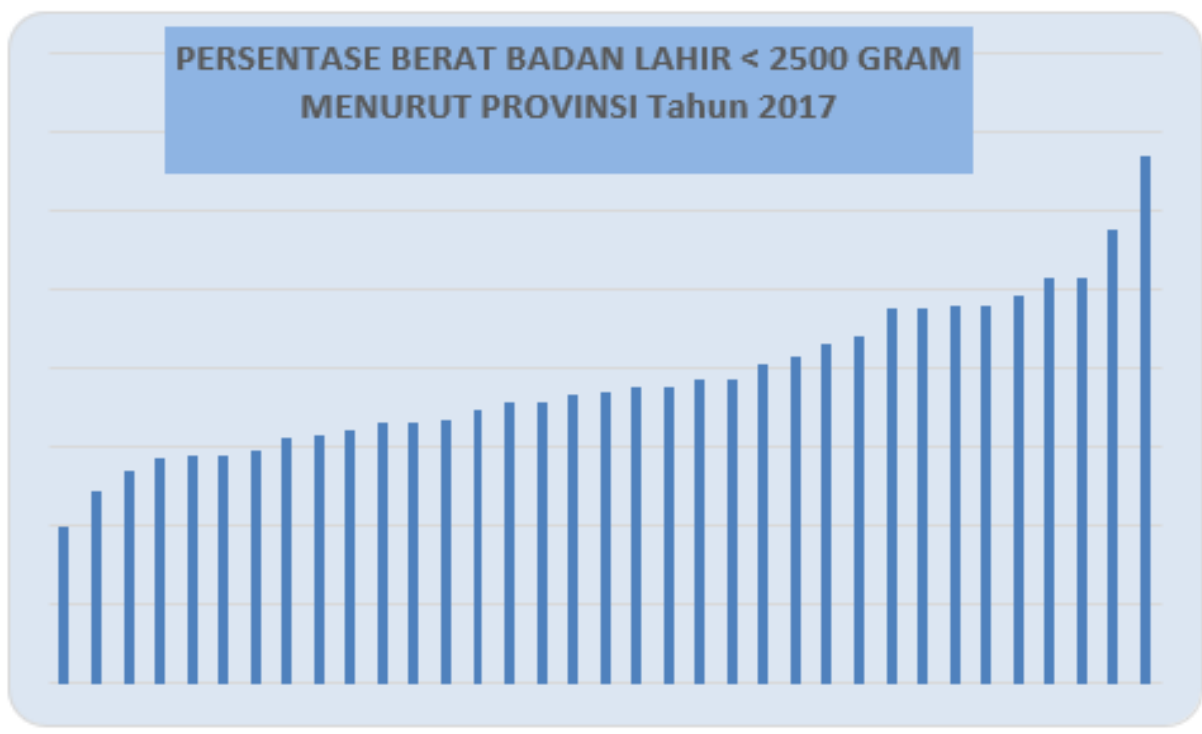

Gambar 1 Grafik Persentase Berat Badan Lahir<2500 Gram Menurut Provinsi Tahun 2017

Banyak faktor penyebab terjadinya BBLR, di antaranya berasal dari faktor kesehatan ibu dan lingkungan sosial serta demografi. Nahar et al. (1998) menunjukkan bahwa lokasi tempat tinggal, pendidikan ibu memengaruhi berat lahir bayi. Agarwal dkk.(2011), menunjukkan bahwa pendidikan ibu dan merokok berpengaruh terhadap BBLR. Bunga, et al (2017), usia kehamilan dan kebiasaan merokok merupakan determinan utama BBLR.

Berdasarkan latar belakang yang telah dipaparkan, permasalahan utama terlihat pada kondisi kesehatan yang dicerminkan/ditunjukkan dari angka BBLR Provinsi Nusa Tenggara Timur pada tahun 2017, yang mana memiliki persentase BBLR tertinggi di Indonesia. Peneliti ingin mengkaji mengenai variabel - variabel yang memengaruhi BBLR di Provinsi Nusa Tenggara Timur pada tahun 2017. Beberapa varibel yang akan diamati, didapatkan melalui studi literatur dari penelitian-penelitian terkait, sehingga didapatkan beberapa faktor yang berpengaruh terhadap BBLR yaitu tempat tinggal, pendidikan ibu, riwayat merokok, dan usia kehamilan.

Penelitian ini mengkaji tentang faktor-faktor yang memengaruhi Berat Badan Lahir Rendah (BBLR) di Nusa Tenggara Timur (NTT) tahun 2017.Penelitian ini terdiri atas 2 variabel, yaitu variabel dependen dan variabel independen. Variabel dependen yang digunakan adalah Berat Badan Lahir Rendah (BBLR) dan variabel independen yang digunakan adalah pendidikan ibu, wilayah tempat tinggal, status merokok, dan usia ibu saat hamil. 
Menurut World Health Organization (WHO) Bayi Berat Lahir Rendah (BBLR) didefinisikan sebagai bayi yang lahir dengan berat $<2500$ gram. Berat lahir adalah berat bayi yang ditimbang dalam waktu 1 (satu) jam pertama setelah lahir.

BBLR dipengaruhi oleh usia ibu pada saat hamil. Usia ibu yang rentan mengalami kejadian BBLR yaitu pada saat usia $i b u<20$ dan $>35$ tahun. BBLR juga dipengaruhi oleh tingkat pendidikan ibu, yang dapat dilihat melalui pengetahuan ibu seperti halnya konsumsi makanan bergizi.Mengonsumsi makanan yang kurang bergizi dapat meyebabkan berat badan ibu tidak mengalami peningkatan, yang nantinya dapat mempengaruhi berat badan janin sehingga dapat berisiko mengalami BBLR. Hal ini memberikan gambaran bahwa tingkat Pendidikan ibu berpengaruh terhadap kejadian BBLR. Semakin rendah pendidikan Ibu, semakin besar peluang terjadinya BBLR. Tingkat Pendidikan ibu dibedakan menjadi 4 kategori, yaitu tidak bersekolah, SD, SMP, dan di atas SMP.

Wilayah tempat tinggal menjadi salah satu faktor yang secara tidak langsung memengaruhi keadaan seorang Ibu yang nantinya dapat berpengaruh terhadap BBLR. Wilayah tempat tinggal terbagi menjadi 2 kategori, yaitu kota dan desa. Wanita hamil yang merokok atau terpapar asap rokok (perokok pasif), beresiko lebih besar mengalami keguguran, atau melahirkan bayi dengan berat badan rendah dan mudah terinfeksi (A. Setiono \& Sri, 2005).

\section{METODE PENELITIAN}

\section{Jenis dan Sumber Data}

Sumber data yang digunakan dalam penelitian ini adalah data sekunder yang diperoleh dari data SDKI 2017 dan merupakan data cross section, yakni data pada tahun 2017.

\section{Metode Analisis}

Metode analisis yang digunakan adalah regresi logistik biner, kerana variabel respon yang digunakan berupa data dikotomik/biner yaitu $1:$ BBLR $<2500$ gram dan 0 : BBLR $\geq 2500$ gram, dengan variabel bebasnya berskala interval dan kategorik.

Metode analisis yang digunakan dalam penelitian ini adalah regresi logistik (Logistic Regression Model), dimana variabel dependennya berbentuk kategorik. Persamaan model regresi logistik dapat diunjukkan pada persamaan (1):

Persamaan :

$$
\pi(x)=\frac{\exp \left(\beta_{0}+\beta_{1} X_{1}+\beta_{2} X_{2}+\beta_{3} X_{3}+\beta_{4} X_{4}\right.}{1+\exp \left(\beta_{0}+\beta_{1} X_{1}+\beta_{2} X_{2}+\beta_{3} X_{3}+\beta_{4} X_{4}\right)}
$$

Tabel 1 Karakteristik Variabel

\begin{tabular}{cl}
\hline Variabel & \multicolumn{1}{c}{ Kategori (Dummy variabel) } \\
\hline \multirow{2}{*}{ Umur (X1) } & $1:<20$ dan $>35$ tahun \\
& $0: 20-35$ tahun* \\
\hline \multirow{2}{*}{ TempatTinggal (X2) } & $1:$ Pedesaan \\
& $0:$ Perkotaan* \\
\hline \multirow{2}{*}{ Status Merokok (X3) $1:$ Merokok } & $0:$ Tidak merokok* \\
\hline \multirow{3}{*}{ Pendidikan (X4) } & $4:$ Tidak bersekolah* \\
& 3: SD \\
& 2:SMP \\
*):kategori referensi &
\end{tabular}

Bentuk transformasi logit dari persamaan model di atas adalah :

$$
\begin{aligned}
g(x) & =\ln \left[\frac{\pi(x)}{1-\pi(x)}\right] \\
& =\beta_{0}+\beta_{1} X_{1}+\beta_{2} X_{2}+\beta_{3} X_{3}+\beta_{4} X_{4}
\end{aligned}
$$


Dimana;

$\boldsymbol{\pi}(\mathrm{x}) \quad=$ peluang kejadian sukses dengan nilai peluang $0 \leq(\mathrm{x}) \leq 1$

$\ln \frac{\pi(x)}{1-\pi(x)} \quad=$ odd ratio

$\beta_{0} \quad=$ intersept

$\beta_{1}, \beta_{2}, \beta_{3}, \beta_{4}=$ koefisien regresi

\section{Uji Signifikansi Parameter Secara Simultan}

Hipotesis :

$H_{0}: \beta_{1}=\beta_{2}=\beta_{3}=\beta_{4}$

$H_{1}$ : sekurang-kurangnya terdapat satu $\beta_{j} \neq 0$

Statistik uji :

$G=-2 \ln \left[\frac{l_{0}}{l_{1}}\right] \sim \chi_{(\alpha ; k)}^{2}$

Dimana;

lo : likelihood dari model tanpa variabel bebas

$l_{l} \quad$ : likelihood dari model dengan variabel bebas

Pengambilan Keputusan :

Tolak $H 0$ saat $G>\chi_{(\alpha ; k)}^{2}$

\section{Uji Signifikansi Parameter Secara Parsial}

Hipotesis :

$H_{0}: \beta_{j}=0$, untuk suatu $\mathrm{j}=0,1, \ldots, \mathrm{p}$

$H_{1}: \beta_{j} \neq 0$

Statistik Uji :

$W_{i}=\left[\frac{\beta_{j}}{\operatorname{se}\left(\beta_{j}\right)}\right]^{2} \sim \chi_{(\alpha ; 1)}^{2}$

Dimana;

$\beta_{\mathrm{j}} \quad=$ Estimasi parameter ke-j

s.e $(\beta)=$ Standar error estimasi parameter ke- $\mathrm{j}$

Pengambilan Keputusan :

Tolak $H_{0}$ saat $W>\chi_{(\alpha ; 1)}^{2}$

Kelebihan metode regresi logistik adalah lebih fleksibel dibanding determinan (Mudrajad, 2001) yaitu antara lain :

a. Regresi logistik tidak memiliki asumsi normalitas atas variabel bebas yang digunakan dalam model. Artinya variabel penjelas tidak harus memiliki distribusi normal linear maupun memiliki varian yang sama dalam setiap grup.

b. Variabel bebas dalam regresi logistik bisa campuran dari variabel kontinyu, diskrit, dan dikotomi.

c. Regresi logistik amat bermanfaat digunakan apabila distribusi respon atas variabel terikat diharapkan non linear dengan satu atau lebih variabel bebas. 


\section{HASIL DAN PEMBAHASAN}

Dalam analisis regresi logistik, ada beberapa uji yang perlu dilakukan untuk menentukan apakah model sudah cukup baik untuk digunakan, yaitu Uji Simultan, Goodness of Fit test, dan Uji Parsial. Berikut hasil output pengolahan data.

\section{Uji Simultan : Omnibus Test}

Tabel 2 Uji Simultan : Omnibus Test

\begin{tabular}{|c|c|c|c|c|}
\hline \multicolumn{5}{|c|}{ Omnibus Tests of Model Coefficients } \\
\hline & & Chi-square & df & Sig. \\
\hline \multirow[t]{3}{*}{ Step 1} & Step & 16.494 & 6 & .011 \\
\hline & Block & 16.494 & 6 & .011 \\
\hline & Model & 16.494 & 6 & .011 \\
\hline \multirow[t]{3}{*}{ Step $2^{\mathrm{a}}$} & Step & -.081 & 1 & .776 \\
\hline & Block & 16.413 & 5 & .006 \\
\hline & Model & 16.413 & 5 & .006 \\
\hline \multirow[t]{3}{*}{ Step $3^{\mathrm{a}}$} & Step & -.319 & 1 & .572 \\
\hline & Block & 16.095 & 4 & .003 \\
\hline & Model & 16.095 & 4 & .003 \\
\hline \multirow[t]{3}{*}{ Step $4^{\mathrm{a}}$} & Step & -.933 & 1 & .334 \\
\hline & Block & 15.162 & 3 & .002 \\
\hline & Model & 15.162 & 3 & .002 \\
\hline
\end{tabular}

Berdasarkan hasil uji simultan, maka dapat dilihat bahwa secara simultan, variabel-variabel mempengaruhi secara signifikan pada step ke 4, dimana pada step 4, p-value untuk uji simultan bernilai 0.002. Nilai ini lebih kecil dari nilai alpha (0.05), yang berarti tolak H0. Hal ini berarti sekurang-kurangnya ada $1 \beta i \neq 0$.

\section{Goodness of Fit test}

\begin{tabular}{cccc}
\multicolumn{4}{c}{ Tabel 3 Hasil Uji Goodness of Fit test } \\
\hline \multicolumn{4}{c}{ Hosmer and Lemeshow Test } \\
\hline Step & Chi-square & df & Sig. \\
\hline 1 & 2.081 & 6 & .912 \\
\hline 2 & .823 & 4 & .935 \\
\hline 3 & .765 & 4 & .943 \\
\hline 4 & .000 & 1 & 1.000 \\
\hline
\end{tabular}

Berdasarkan hasil uji pada table di atas, dapat dilihat bahwa pada step ke 4, nilai p-value bernilai 1, yang lebih besar dari alpha (0.05), yang berarti gagal tolak H0. Kondisi gagal tolak H0 menunjukkan bahwa nilai observasi (oi) dan nilai ekspektasi yang berasal dari model (ei) tidak memiliki perbedaan yang signifikan, sehingga dapat dikatakan bahwa model adalah model yang fit. 


\section{Estimasi Parameter \& Uji Parsial}

Tabel 4 Estimasi Parameter \& Uji Parsial

\begin{tabular}{|c|c|c|c|c|c|c|c|}
\hline \multicolumn{8}{|c|}{ Variables in the Equation } \\
\hline & & B & S.E. & Wald & df & Sig. & $\operatorname{Exp}(B)$ \\
\hline \multirow[t]{8}{*}{ Step $1^{\mathrm{a}}$} & kelopokuur(1) & -.062 & .217 & .081 & 1 & .776 & .940 \\
\hline & Smokes cigarettes $(1)$ & .301 & .548 & .301 & 1 & .583 & 1.351 \\
\hline & pend & & & 12.170 & 3 & .007 & \\
\hline & pend(1) & -1.636 & .648 & 6.381 & 1 & .012 & .195 \\
\hline & pend(2) & -.655 & .538 & 1.484 & 1 & .223 & .519 \\
\hline & pend(3) & -.276 & .537 & .265 & 1 & .606 & .758 \\
\hline & $\operatorname{tmtpt}(1)$ & -.248 & .263 & .890 & 1 & .346 & .780 \\
\hline & Constant & -1.282 & .740 & 3.002 & 1 & .083 & .278 \\
\hline \multirow[t]{7}{*}{ Step $2^{\mathrm{a}}$} & Smokes cigarettes $(1)$ & .299 & .548 & .298 & 1 & .585 & 1.349 \\
\hline & pend & & & 12.825 & 3 & .005 & \\
\hline & pend(1) & -1.659 & .643 & 6.670 & 1 & .010 & .190 \\
\hline & pend(2) & -.669 & .536 & 1.558 & 1 & .212 & .512 \\
\hline & pend(3) & -.283 & .536 & .280 & 1 & .597 & .753 \\
\hline & $\operatorname{tmtpt}(1)$ & -.251 & .263 & .910 & 1 & .340 & .778 \\
\hline & Constant & -1.308 & .734 & 3.175 & 1 & .075 & .270 \\
\hline \multirow[t]{6}{*}{ Step $3^{a}$} & pend & & & 12.694 & 3 & .005 & \\
\hline & pend(1) & -1.637 & .641 & 6.526 & 1 & .011 & .195 \\
\hline & pend(2) & -.639 & .533 & 1.439 & 1 & .230 & .528 \\
\hline & pend(3) & -.260 & .534 & .238 & 1 & .626 & .771 \\
\hline & $\operatorname{tmtpt}(1)$ & -.258 & .263 & .966 & 1 & .326 & .773 \\
\hline & Constant & -1.040 & .541 & 3.687 & 1 & .055 & .354 \\
\hline \multirow[t]{5}{*}{ Step $4^{\mathrm{a}}$} & pend & & & 12.467 & 3 & .006 & \\
\hline & pend(1) & -1.651 & .640 & 6.649 & 1 & .010 & .192 \\
\hline & pend(2) & -.665 & .531 & 1.567 & 1 & .211 & .514 \\
\hline & pend(3) & -.295 & .532 & .309 & 1 & .578 & .744 \\
\hline & Constant & -1.224 & .509 & 5.786 & 1 & .016 & .294 \\
\hline
\end{tabular}

a. Variable(s) entered on step 1: kelopokuur, Smokes cigarettes, pend, tmtpt.

Tabel di atas menunjukkan bahwa variabel pendidikan berpengaruh signifikan terhadap kejadian BBLR. Hal ini terlihat dari p-value sebesar 0,006, di mana p-value tersebut kurang dari alpha (5\%) yang berarti tolak Ho. Sehingga berdasarkan output, model regresi logistik yang terbentuk adalah sebagai berikut;

$$
\hat{g}(\mathrm{x})=-1,224-1,651 X_{41}-0,665 X_{42}-0.295 X_{43}
$$

Interpretasi dari model tersebut adalah sebagai berikut :

1. Kecenderungan bayi untuk BBLR dengan Pendidikan ibu SMA 0,192 kali lebih kecil dibanding pendidikan ibu yang tidak bersekolah

2. Kecenderungan bayi untuk BBLR dengan Pendidikan ibu SMP 0,514 kali lebih kecil dibanding pendidikan ibu yang tidak bersekolah

3. Kecenderungan bayi untuk BBLR dengan Pendidikan ibu SD 0,744 kali lebih kecil dibanding pendidikan ibu yang tidak bersekolah

Hasil ini sesuai dengan hasil penelitian dari Rosela dkk (2016), yang menyebutkan bahwa pendidikan Ibu berpengaruh signifikan terhadap kejadian BBLR. Selain itu, dapat dilihat pula bahwa variabel usia Ibu, tempat tinggal, dan status merokok tidak berpengaruh secara signifikan terhadap kejadian BBLR di NTT pada tingkat signifikansi $5 \%$. 


\section{KESIMPULAN}

Berdasarkan penelitian yang telah dilakukan, dapat disimpulkan bahwa variabel yang berpengaruh secara signifikan pada tingkat signifikansi 5\% terhadap kejadian Berat Badan Lahir Rendah (BBLR) di NTT tahun 2017 yaitu tingkat pendidikan ibu, sedangkan variabel usia ibu, tempat tinggal, dan status merokok tidak berpengaruh secara signifikan. Secara umum semakin tinggi tingkat pendidikan ibu, maka kecenderungan mengalami kejadian Berat Badan Lahir Rendah (BBLR) semakin kecil.

\section{DAFTAR PUSTAKA}

Agarwal, K., Agarwal, A., Agrawal, V., Agrawal, P. dan Chaudhary, V. (2011). Prevalence and determinants of"' low birth weight" among institutional deliveries.Annals of Nigerian Medicine, 5(2), 48.

Agresti, A. 2002. Categorical Data Analysis. Second Edition. New Jersey: John Wiley and Sons, INC.

BAPPENAS, BPS, UN POPULATION FUND. Proyeksi Penduduk Indonesia 2010-2035 (Hal.20).2013. Jakarta-Indonesia.

BKKBN, BPS, Kemenkes. 2018. Survei Demografi dan Kesehatan Indonesia 2017. Jakarta: Badan Kependudukan dan Keluarga Berencana Nasional.

Bunga, et al (2017). “Analisis Determinan Berat Bayi Lahir Rendah (BBLR) Pada Anak Usia 0-59 Bulan di NTT, Kalimantan Tengah, dan Papua”

Hafid, Wahyuni; Fraining Deisi Badu; dan Lili Pramutia Laha. 2018. Analisis Determinan Kejadian Berat Badan Lahir Rendah (BBLR) di RSUD Tani dan Nelayan. Gorontalo of Public Health.1(1). 1 - 7.

Kuncoro, Mudrajad. 2001. Metode Kuantitatif Teori Dan Aplikasi Untuk Bisnis Dan Ekonomi. AMP YKPN. Yogyakarta

Kristin Rosela, Etri Taviane, dan Rena Oky Alestari. 2016. Pengaruh Pendidikan Kesehatan Terhadap Tingkat Pengetahuan Ibu Hamil Dalam Pencegahan Terjadinya Kelahiran Bayi Berat Badan Lahir Rendah (BBLR) di Wilayah Kerja UPTD Puskesmas Pahandut Palangkaraya. Dinamika Kesehatan. 7(2). 60 67.

Mahdalena, Hj.Endang Sri P Ningsih, H.Sugian Noor. 2014. Pengaruh Rokok Terhadap Berat Bayi Lahir Rendah di RSUD Banjarbaru. Jurnal Skala Kesehatan.5(2).1-6.

Nahar, N., Afroza, S. dan Hossain, M. (1998).Incidence of low birth weight in three selected communities of Bangladesh. Bangladesh Med Res Counc Bull, 24(2), 49-54. 